\title{
From channel proteins to industrial biomimetic membrane technology
}

\author{
Pedersen, Per Amstrup; Bjørkskov, Frederik Bühring; Alvisse, Simon; Hélix-Nielsen, Claus
}

Published in:

Faraday Discussions

Link to article, DOI:

$10.1039 / \mathrm{c} 8 \mathrm{fd} 00061 \mathrm{a}$

Publication date:

2018

Document Version

Peer reviewed version

Link back to DTU Orbit

Citation $(A P A)$ :

Pedersen, P. A., Bjørkskov, F. B., Alvisse, S., \& Hélix-Nielsen, C. (2018). From channel proteins to industrial biomimetic membrane technology. Faraday Discussions, 209, 287-301. https://doi.org/10.1039/c8fd00061a

\section{General rights}

Copyright and moral rights for the publications made accessible in the public portal are retained by the authors and/or other copyright owners and it is a condition of accessing publications that users recognise and abide by the legal requirements associated with these rights.

- Users may download and print one copy of any publication from the public portal for the purpose of private study or research.

- You may not further distribute the material or use it for any profit-making activity or commercial gain

- You may freely distribute the URL identifying the publication in the public portal

If you believe that this document breaches copyright please contact us providing details, and we will remove access to the work immediately and investigate your claim. 


\section{RSCPublishing Faraday Discussions}

\section{TBC}

\begin{tabular}{|r|l|}
\hline Journal: & Faraday Discussions \\
\hline Manuscript ID & FD-ART-03-2018-000061 \\
\hline Article Type: & Paper \\
\hline Date Submitted by the Author: & $07-$ Mar-2018 \\
\hline Complete List of Authors: & $\begin{array}{l}\text { Pedersen, Per; Kobenhavns Universitet Biologisk Institut } \\
\text { Bjørkskov, Frederik; Kobenhavns Universitet Biologisk Institut } \\
\text { Alvisse, Simon; Aquaporin Asia } \\
\text { Helix-Nielsen, Claus; Technical University of Denmark, Department of } \\
\text { Environmental Engineering }\end{array}$ \\
\hline
\end{tabular}

\section{SCHOLARONE \\ Manuscripts}




\section{From channel proteins to industrial biomimetic membrane}

\section{technology}

Per Amstrup Pedersen ${ }^{1}$, Frederik Bühring Bjørkskov ${ }^{1}$, Simon Alvisse ${ }^{2}$, and Claus HélixNielsen ${ }^{3,4,5, *}$

${ }^{1}$ Department of Biology, Molecular and Integrative Physiology, University of Copenhagen, DK 2200 Copenhagen Denmark

${ }^{2}$ Aquaporin Asia, Pte, Ltd, Singapore, 1 CleanTech Loop \#03-05 CleanTech One, 637141 Singapore

${ }^{3}$ Department of Environmental Engineering, Technical University of Denmark, DK2800 Kgs. Lyngby, Denmark

${ }^{4}$ Aquaporin A/S, Nymøllevej 78, DK2800 Kgs. Lyngby Denmark

${ }^{5}$ University of Maribor, Faculty of Chemistry and Chemical Engineering

Smetanova ulica 17, 2000 Maribor, Slovenia

* Corresponding author:

Claus Hélix-Nielsen

Department of Environmental Engineering,

Building 115, office 140

Technical University of Denmark,

DK2800 Kgs. Lyngby, Denmark

EMB: clhe@env.dtu.dk

TEL: +4545252228

FAX: +4545932850 


\begin{abstract}
Biomimetic membrane technology, based on the use of nano-scale functional additives in the form of channel proteins or artificially made channel structures, represents an attractive way of optimizing membrane separation technology. However, the nano-scale nature of the additives inherently points to the challenge in up-scaling the membranes to square meter areas. Thus, the ability to up-scale the processes involved in manufacturing will be crucial for translating the protein/nano-science into technology. Here we discuss how the use of highly selective aquaporin proteins can be used to enhance the performance of the classical thin film composite membrane, and how this can be used in relevant membrane element and module form factors. A particular up-scaling challenge lies in securing large scale membrane protein production We demonstrate our framework for making batch amounts which are compatible with large scale production of biomimetic membranes for water purification based on the use of the E. coli expression system.
\end{abstract}

KEY WORDS: aquaporin membranes, biomimetics, water purification, desalination 


\section{Introduction}

As membranes are increasingly being integrated in a wide range of processes the need for high stability, high efficiency, and low energy requirement is also increasing. For many years traditional membrane technology has been based on polymeric films with an inverse correlation between permeability and selectivity. The use of polymeric structures enables tailoring the permeability properties ranging from macromolecular and molecular separation using microfiltration (MF) and ultrafiltration (UF) membranes to small molecule and ionic separation using nanofiltration (NF) and osmotic membranes - both forward osmosis (FO) and reverse osmosis (RO) membranes. To achieve efficient separation of ions and low molecular $(<50 \mathrm{Da})$ solutes while at the same time have an efficient transport of solvent (typically water) it is desirable to be able to control the nano-scale structure and dynamics of the transporting structures. Both naturally occurring protein structures as well as artificially de novo designed nano-scale structures may indeed provide means to obtain this control and thereby constitute building blocks for making membranes with highly efficient separation [1].

The discovery of water channel proteins - aquaporins - has resulted in several membrane designs where these proteins are used as the functional unit, for reviews see [2,3]. These designs have in various ways addressed the stability challenge arising from the fact that the aquaporin protein in cellular membranes spans a membrane of only 3-4 nanometer thickness. Incorporating aquaporin proteins or self-assembling artificial channel structures into compatible materials, while ensuring industrial production scalability will be decisive for translating the nano-scale science into a successful technology. But not only the selection of materials for incorporation is critical - also the ability to produce the (self-assembling) building blocks (aquaporins or artificially made channels) as well as developing the optimal membrane form factors (membrane elements) in large quantities will be decisive for successful large scale technological applications.

FO and RO membranes are both highly selective membranes and therefore ideal starting points for testing new flux and rejection enhancing structural additives. RO and FO differ in their operational use: water transport through RO is driven by hydraulic transmembrane pressure [4] whereas water transport 
through FO membranes is driven by osmotic transmembrane where the osmotic driving force is arising from having the FO membrane separating a feed solution of low osmolarity from a draw solution with high osmolarity [5]. Both membranes can be characterized in terms of water flux $J_{w}$ and solute (salt) flux $J_{s}$ For both RO and FO a high $J_{w}$ and low $J_{s}$ is desirable. In RO both $J_{w}$ and low $J_{s}$ are representing transport in the same direction (from feed to permeate) whereas for FO the two are representing transport in opposite directions ( $J_{w}$ from feed to draw and $J_{s}$ from draw to feed). The difference in driving force necessitates a difference in membrane physical-chemical structure in order to avoid issues of concentration polarisation inside the membrane material. This intensely studied subject is beyond the scope of this communication, for recent reviews please see $[5,6]$. But beyond the concentration polarization issue, the fact that RO transmembrane pressures in some cases can exceed 100 bar, may have impact on the stability of the flux and rejection enhancing structural additives.

Here we will discuss how we have addressed these challenges in biomimetic RO and FO membrane production: the issues in large scale membrane manufacturing and element designs as well as producing aquaporin proteins in large (gram) scale quantities.

\section{Large scale membrane manufacturing and element designs}

Polyamide thin-film-composite flat sheet (TFC) membranes can be seen as the canonical membrane type for high demanding separation application such as seawater desalination produced in large scale. Flat sheet TFC membranes consist of a thin polyamide film formed on a microporous typically polysulfone (PS) support material by polycondensation reactions of an amine such as $\mathrm{m}$ phenylenediamine (MPD) and an acid chloride monomer such as trimesoyl chloride (TMC) [7]. The porous support material is typically casted on a thin fabric giving the finished TFC polyamide membrane a three-layered structure starting with the fabric (e.g. non-woven polyester of $\sim 100 \mu \mathrm{m}$ thickness) as backing, then the intermediate casted microporous PS layer ( $\sim 5 \mu \mathrm{m}$ thickness), and the polyamide separation layer ( 100-200 nm thickness) on top.

We have used this scheme to enable production of flat sheet TFC membrane in a roll-to-roll process starting with phase-inversion-based casting of the PS microporous membrane using an organic solvent where the critical parameters are the PS concentration of the casting organic solvent (e.g. 
dimethylacetamide (DMA)) solution and the line speed (the speed at which the fabric is passing the casting process) and the resulting membrane thickness. For the coating (TFC) process the critical parameters are the tension of the PS membrane sheet, the immersion time of the PS sheet in the MPD aqueous solution and the ensuing polyamide formation reaction time involving MPD and TMC). After the TMC-MPD reaction the cross-linked membrane is typically heated, and the membrane can undergo a series of post-coating modification/stabilization steps resulting in the final membrane sheet roll.

Figure 1 shows the basic outline of the processes.

Figure 1 around here

Our manufacturing process represents one version of the generic industrial standard for producing large quantities of membranes with high selectivity. As the coating process involves formation of an interfacial reaction layer with MPD in aqueous phase mixing with TMC in organic phase the integration of flux- and selectivity enhancing elements (e.g. aquaporins or artificially made channel structures) may take place via either phase. In our case we use the aqueous phase as medium for addition of polymeric vesicles with aquaporin proteins following the approach by Zhao et al. [8]. The main reason being this is that the polymeric vesicle self-assembly takes place in an aqueous phase. But in principle any flux and rejection additive may be added via either phase. However if self-assembly is required for the additives to be functional (which is the case for aquaporin proteins) then the balanced effects from the phases is crucial - as exemplified by the role played by the hydrophobic effect in membrane protein self-assembly.

\section{Element form factors}

The flat sheet membrane sheet roll is then used in fabrication of modules where the spiral wound (SW) element is the representative form factor. The SW form factor allows for a high packing density $\left(\mathrm{m}^{2}\right.$ of membrane per $\mathrm{m}^{3}$ element volume) where elements for reverse-osmosis (RO) mediated desalination of seawater can reach packing densities as high as $1200 \mathrm{~m}^{2} / \mathrm{m}^{3}$ (as evidenced by the 8 inch desalination 
RO elements from Toray). To achieve this packing density, the distance between membrane layers has to be $<1 \mathrm{~mm}$. This implies that the necessary feed and permeate spacers allowing for the flow in the elements are relatively thin $(50-200 \mu \mathrm{m})$. As a consequence the SW element is difficult to clean and the compact design makes the membrane fouling propensity high. This can to some extend be alleviated via adequate pretreatment of the feed stream.

SW elements are typically used in RO applications - from low pressure (tap water) RO over medium pressure brackish water (BW) RO to high pressure RO seawater desalination. For FO SW elements, membrane packing densities cannot reach the same values as is the case for SW RO elements. The main reason for this is that in FO there must be a flow of feed and draw solutions on either side of each individual membrane leaflet. This requirement increases the total thickness of spacers between membrane layers and subsequently decreases the packing density. Thus the applications of SW FO elements are limited to cases where feed water streams contain low concentrations of foulants. We have taken this as a starting point and have made a series of tap water RO (TWRO) aquaporin-based membranes for use in household water purifiers based on the SW form factor, see Figure 2

Figure 2 around here

Flat sheet membranes may also be fitted in so-called plate-and-frame (PAF) membrane modules. The elements consist of flat sheet membranes separated by a spacer mesh and sealed to frames. The individual frames forms cassettes with feed stream flowing outside the cassette and permeate flowing in the inner volume of the cassette for subsequent collection. Cassettes are stacked to form the complete PAF element. Due to the less compact design compared to SW elements the PAF elements can be used in demanding water treatment applications characterized by steam containing high amounts of foulants and/or having high viscosities. We have tried to fabricate PAF FO modules but found it difficult to achieve efficient flow patterns with minimal unstirred volumes. 
Besides flat sheet membranes, cylindrically shaped membranes are also used in more specialized applications. The latter membrane type comprises tubular membranes (TM) and hollow fiber (HF) membranes where the main difference is in the inner lumen diameter of the membrane cylinder with $\mathrm{TM}$ tubes having diameters in the mm range and HF fibers having diameters in the $\mu \mathrm{m}$ range.

TM membrane are essentially porous tubes with inner diameters ranging from $5 \mathrm{~mm}$ to $15 \mathrm{~mm}$ coated with micro-porous layers of PVDF or PES on either the inside or outside walls. Depending on the orientation of the coating layer, TM modules where the individual TM membranes are fitted into a cylindrical housing - are either operated in outside-in or inside-out configurations with feed streams flowing outside or inside individual tubes respectively. TM modules based on tubular membranes are typically used in UF applications with high fouling / high viscosity waste water streams. From an FO module point of view, TM modules can be seen as an alternative to PAF modules in demanding applications. Compared to PAF modules, TM modules offer higher packing density and easier sealing between membrane and housing (as the TM tubes can be 'glue-potted' in both ends) [4]. On the other hand TM tubes have wall thicknesses (including the PVDF or PES micro-porous layer) can be too large for FO processes giving rise to an induced internal concentration polarization in the tube wall [9].

We have used UF TM membranes as substrate for making FO membranes by coating with a TFC layer formed from interfacial polymerization and aquaporin addition as described above. TM FO membranes may be used in food and beverage applications where potentially high levels of concentration for a variety of liquid foods and food ingredients may be achieved even for highly viscous streams. This research area is increasingly attracting attention and has been described in several reviews [10-12].

We chose coconut milk as a challenging feed stream to be up-concentrated. Coconut milk and cream is found in many traditional Indian and Southeast Asian cuisines, in sweet and savory dishes. Today Indonesia and Thailand are some of the world's largest exporters and consumers of coconut milk. Coconut milk beverages, containing less than $1-2 \%$ fat, are increasingly being recognized as 
competitors to soya and almond milk products in the United States and Europe; for a comprehensive introduction to coconut food industry see [13]. Also, coconut milk is gaining interest as a dietary substitute for lactose intolerant consumers, and many brands are already diversifying their beverage offerings to include coconut milk. Recent studies have also pointed to the beneficial effects of coconut milk oil medium chain triglycerides for treating diseases such as dementia (Alzheimer's disease) [14].

Coconut milk is a thixotropic fluid (similar to yoghurt), a type of non-Newtonian fluid with timedependent viscosity where viscosity diminishes with time when the fluid is subjected to a constant speed gradient. As dewatering will lead to an increase in viscosity the FO membrane module must be designed to accommodate this increase.

Figure 3 around here

We attempted up-concentration of a coconut milk solution using Aquaporin Inside ${ }^{\mathrm{TM}}$ Tubular FO membrane modules, see Fig. 3. The feed solution was operated in a batch mode to attain a higher recovery. The draw solution was operated in a continuous mode to maintain a sufficient driving force. The experiment was performed in FO mode where active layer of the membrane is facing the feed side. Details of the experimental setup are summarized in Fig. 3.

With batch concentration operations and $1 \mathrm{M} \mathrm{NaCl}$ draw solution, it was possible to up-concentrate the $10 \mathrm{~kg}$ coconut milk $2 \mathrm{x}$ corresponding to approximately $50 \%$ recovery. Water is recovered from the coconut milk to the draw solution with time, see Fig. 4a. The initially measured viscosity increased from 700 to $5000 \mathrm{cP}$ whereas the equilibrium viscosity increased from 500 to $800 \mathrm{cP}$ reflecting the thixotropic nature of the coconut milk, see Fig. 4b. For sanitary reasons it is crucial that the membrane modules (and any food contact material) can be cleaned. This was tested using a standard cleaning protocol, see Fig. 4c, and the results are shown in Fig. 4d. As can be seen, both the water flux $J_{s}$ and 
reverse salt flux $J_{s}$ were similar before and after cleaning demonstrating the feasibility to use tubular FO modules for coconut milk up-concentration.

Figure 4 around here

We have also developed a HF FO module based on the TFC aquaporin membrane coating procedure described above, see Fig. 5. HF modules are basically tubular modules with very high packing densities and are used in a variety of applications including seawater desalination. However, HF membranes are prone to fouling and clogging due to their small $(\sim 100-400 \mu \mathrm{m})$ fiber lumen diameters, and use may thus involve various levels of pretreatment. Still HF FO modules have potential in rejection low molecular weight compounds. In a recent study Engelhardt et al. tested a HF FO aquaporin membrane module with respect to rejection of three different trace organic contaminants: the herbicide 2,4dichlorophenoxyacetic acid (2,4-D), the plastic component bisphenol A (BPA) and the preservative methyl paraben [15]. Over $95 \%$ of methyl paraben was rejected by the membrane while for 2,4-D and BPA rejection rates of over $99 \%$ were attained although with some apparent adsorption of BPA and methyl paraben on the aquaporin membrane. This phenomenon may have to be addressed in future studies by developing specific cleaning protocols for ABMs.

Figure 5 around here 


\section{Large scale protein production}

Industrial scale production of biomimetic membranes requires routine access to pure and functional recombinant membrane proteins preferentially on the gram scale. However, even at the laboratory scale high yield recombinant membrane protein production is definitely not a trivial task. Industrial scale production and purification is almost uncharted land as commercial large scale providers of membrane proteins are to our knowledge almost non-existing. As an example we will present the initial steps required for upscale of production and purification of the bacterial AqpZ aquaporin isoform in the Escherichia coli bacterial production system.

\section{Production of AqpZ in E. coli}

As host-vector system for AQPZ production we selected the classical BL21(DE3), pET58 system [16] that allows inducible expression. To simplify production and purification optimization we settled out to study expression and purification of AqpZ N-terminally fused to a histidine tagged green fluorescent protein (GFP) as depicted in Figure 6. Presence of GFP allows one to follow accumulation of AqpZ in E.coli cells by measuring fluorescence in intact cells and identify the presence and quality of the recombinant protein during purification.

Figure 6 around here 


\section{Accumulation of Hiss-GFP-AqpZ is favored at $15^{\circ} \mathrm{C}$.}

We have previously demonstrated [17-20] that recombinant membrane proteins accumulate to a much higher membrane density at $15^{\circ} \mathrm{C}$ compared to the optimal growth temperature of the host organism, in this case $37^{\circ} \mathrm{C}$. To investigate if this was also the case for production of AqpZ in E. coli we followed accumulation of $\mathrm{His}_{8}$-GFP-AqpZ after induction of expression at $15^{\circ} \mathrm{C}$ or $37^{\circ} \mathrm{C}$. As is evident from Figure 7, $\mathrm{His}_{8}$-GFP-AqpZ accumulated to a 5 fold higher density when produced at $15^{\circ} \mathrm{C}$ relative to production at $37^{\circ} \mathrm{C}$. Importantly enough accumulation was furthermore stable for a long time at $15^{\circ} \mathrm{C}$ while expression peaked after around 20 hours of induction at $37^{\circ} \mathrm{C}$ and leveled off very fast. So cooling of the expression host prior to induction of AqpZ production is of crucial importance for maximizing the yield.

Figure 7 around here

\section{LDAO and DDM efficiently solubilizes His 8 -GFP-AqpZ}

A particular challenge in the purification of membrane proteins is that they need to be extracted from the membrane without affecting their stability and biological activity. Identifying the right detergent is therefor of crucial importance for successful purification. We performed a small screen to identify a detergent that can solubilize the recombinant $\mathrm{His}_{8}$-GFP-AqpZ from E. coli membranes with high efficiency. The data in Figure 8 show that the zwitter ionic detergent LDAO (Lauryldimethylamine-NOxide) as well as the non-ionic detergent DDM (n-Dodecyl--D-Maltoside) solubilized His 8 -GFP-AqpZ with efficiencies around $90 \%$. This is excellent as the price of detergents is the the major cost in purifying membrane proteins on a large scale. 
Figure 8 around here

\section{FSEC of detergent solubilized His H $_{8}$-GFP-AqpZ indicates a good protein quality}

In addition to a high solubilization efficiency it is of crucial importance that the solubilized protein maintains its structure and its biological activity over time. A simple way to screen for good quality of a solubilized membrane protein is to use Fluorescence Detection Size Exclusion Chromatography (FSEC) [21]. This can be achieved on a semi high-throughput scale due to presence of the GFP tag in the fusion protein. Elution of the GFP tagged protein as a single mono-disperse peak indicates that the solubilized protein is homogeneous and not aggregated. We therefore performed FSEC on the crude membranes used for the solubilization screen in Figure 8. It can be seen from Figure 9 that both detergents resulted in a mono disperse elution profile indicating an excellent quality of both the LDAO and DMM solubilized $\mathrm{His}_{8}$-GFP-AqpZ. In fact the two profiles are super imposable indicating that they equally good at maintaining the structure of AqpZ. 


\section{AqpZ can be purified by affinity chromatography}

To develop a purification strategy based on Ni-affinity chromatography we investigated the elution profile of LDAO solubilized $\mathrm{His}_{8}$-GFP-AqpZ after binding to the Ni-resin. The data in Figure 10 show that the majority of the protein elutes at an Imidazol concentration of $250 \mathrm{mM}$ and that the protein eluting from the affinity column has the expected molecular weight around $33 \mathrm{kDa}$. The apparent molecular weight is around $33 \mathrm{kDa}$ as correctly folded and fluorescent GFP only adds around $10 \mathrm{kDa}$ to the $23 \mathrm{kDa}$ of AqpZ.

Figure 10 around here

\section{Hiss-GFP-AqpZ can be produced in high yield in $E$. coli}

The amount of His ${ }_{8}$-GFP-AqpZ that can be produced in E. coli depends on the amount accumulating per cell, the cell density that can be reached in a bioreactor and the working volume. To estimate the potential for AqpZ production in E. coli we used the GFP fluorescence to quantify the amount of His $8^{-}$ GFP-AqpZ accumulating by use of a GFP standard curve (4). In a 1 liter shake flask with an $\mathrm{OD}_{450}$ of 4 we obtained 4,000,000 fluorescence units (FUs) corresponding to 1,000,000 FUs per liter per OD 450 . This corresponds to the production of around $45 \mathrm{~g}$ per 100 liter growth medium at an $\mathrm{OD}_{450}=100$ in a bioreactor; a cell density that has previously been described in the literature.

\section{Materials and Methods}

\section{Temperature optimization of AqpZ production.}

BL21(DE3) E.coli cells (1) transformed with the expression plasmid from Figure 1 were inoculated in 2 liters of 2xYT medium (16 g/L Tryptone, $10 \mathrm{~g} / \mathrm{L}$ Yeast Extract, $5.0 \mathrm{~g} / \mathrm{L} \mathrm{NaCl} \mathrm{pH} \mathrm{7.5)} \mathrm{to} \mathrm{an} \mathrm{OD}_{450}=$ 


\section{Paper prepared for Faraday Discussions}

0.05 at room temperature. At $\mathrm{OD}_{450}=0.6$ the culture was separated in two and one half was transferred to $37^{\circ} \mathrm{C}$ while the other was transferred to $15^{\circ} \mathrm{C}$. Protein production was induced after 15 minutes thermo equilibration by addition of $1 \mathrm{mM}$ IPTG. Samples were withdrawn at various time points after induction and $\mathrm{His}_{8}$-GFP-AqpZ accumulation was quantified by measuring GFP fluorescence in intact cells as described below.

\section{Measurement of GFP fluorescence in intact E.coli cells}

$1 \mathrm{OD}_{450}$ unit of E.coli cells were harvested by centrifugation at 12,000 $\mathrm{g}$ for 2 minutes. The pellet was washed once in $0.9 \%(\mathrm{w} / \mathrm{v}) \mathrm{NaCl}$, subsequently resuspended in $200 \mu \mathrm{l}$ of $0.9 \% \mathrm{NaCl}$ and transferred to a white micro plate (Nucleon Nunc). Fluorescence in each sample was quantified using a spectrofluorometer (Fluoroskan Ascent, Thermo Scientific) using 0.9\% $\mathrm{NaCl}$ as a blank. Excitation was at $485 \mathrm{~nm}$ and emission at $520 \mathrm{~nm}$.

\section{Preparation of crude membranes from E.coli}

Cells were resuspended in $20 \mathrm{ml}$ ice cold lysis buffer (25mM Imidazol, $1 \mathrm{mM}$ EDTA, $1 \mathrm{mM}$ EGTA, 10\% (w/v) Glycerol pH7.6) including protease inhibitors; 1mM PMSF, $1 \mu \mathrm{g} / \mathrm{ml}$ Leupeptin Chymostatin and Pepstatin. Cells were disrupted at $4^{\circ} \mathrm{C}$ by sonication using a Bandelin-Sonoplus 3100 for 15 minutes using Pulsation ON (puls ON 5 seconds and puls Off 5 seconds). Cell debris was removed by centrifugation at $24,000 \mathrm{~g}$ for 10 minutes at $4^{\circ} \mathrm{C}$ using the Sorvall SS-34 rotor. The membrane content of the supernatant was isolated by ultracentrifugation at $150,000 \mathrm{~g}$ for 1.5 hours at $4^{\circ} \mathrm{C}$. The membrane pellet was resuspended in $5 \mathrm{ml}$ Lysis buffer containing protease inhibitors and kept at $-80^{\circ} \mathrm{C}$ until use.

\section{Solubilization of His-GFP-AqpZ}

Crude membranes were incubated in buffer B $(25 \mathrm{mM}$ Tris-HCl, $10 \mathrm{mM}$ Imidazole, $0.5 \mathrm{M} \mathrm{NaCl}, 10 \%$ glycerol, $\mathrm{pH}$ 7.6) supplemented with protease inhibitors (1 mM PMSF and $1 \mu \mathrm{g} / \mathrm{ml}$ Leupeptin, Chymostatin and Pepstatin, respectively) at a protein to detergent ratio (w/w) of 1:3. The sample was subsequently incubated on a blood roller at $4{ }^{\circ} \mathrm{C}$ for 1 hour. Solubilized proteins were separated from non-solubilized material by ultra-centrifugation at $70,000 \mathrm{rpm}$ for 30 minutes at $4^{\circ} \mathrm{C}$ in a Beckman 
Optima TMTLX ultracentrifuge fitted with an S.N. 96U 826 rotor. Fluorescence was detected in white micro plates (Nucleon Nunc) in a spectro fluorometer (Fluoroskan Ascent, Thermo Scientific) using buffer as a blank. Excitation was at $485 \mathrm{~nm}$ and emission at $520 \mathrm{~nm}$. Solubilization efficiency was estimated as percentage fluorescence left in the supernatant of solubilized samples compared to fluorescence in the initial crude membrane fractions.

\section{Fluorescent size exclusion chromatography (FSEC)}

Solubilized crude membranes were analyzed by fluorescence size exclusion chromatography (FSEC) on a Superose 6 increase 10/300 column attached to an ÄKTA Purifier (GE Healthcare, USA), using FSEC buffer (20 mM TRIS-HCl, 0.15 M NaCl, $0.03 \%$ (w/v) DDM). The effluent from the column was coupled to a fluorescence detector (Shimadzu Prominence RF-20A) to measure fluorescence and visualize the elution profile of the GFP tagged AqpZ.

To estimate the molecular weight of the solubilized channels, a comparison was done using the HMW calibration kit from GE Healthcare dissolved at $20 \mathrm{mg} / \mathrm{ml}$ in FSEC buffer. The molecular masses were: Ovalbumin 43 kDa; Conalbumin 75 kDa; Aldolase 158 kDa; Ferritin 440 kDa; Thyroglobulin 669 kDA; Blue Dextran 2000 kDa. The elution volume for Blue Dextran defined the void volume.

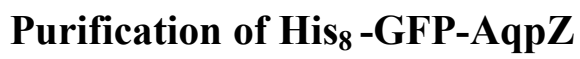

Crude membranes were solubilized for four hours at $4^{\circ} \mathrm{C}$ by slow rotation in LDAO at a protein to detergent ration of 1 to 3 . The solubilized protein was isolated by ultracentrifugation at $4^{\circ} \mathrm{C}$ for 30 minutes at 160,000 rpm. The solubilized protein was diluted to a detergent concentration corresponding to 1.5 times CMC and incubated overnight in a beaker with Ni-resin (Genscript, USA). The beaker content was transferred to a $2 \mathrm{ml}$ CellThru disposable column (Clontech, USA). After collection of the run through, the column was washed with Buffer containing $10 \mathrm{mM}, 30 \mathrm{mM}, 100 \mathrm{mM}, 250 \mathrm{mM}$ or 500 $\mathrm{mM}$ imidazole. All buffers contained detergent at a concentration corresponding to 1.5 times CMC. Fluorescence in each fraction was quantified using a spectrofluorometer (Fluoroskan Ascent, Thermo Scientific) using buffer as a blank. Excitation was at $485 \mathrm{~nm}$ and emission at $520 \mathrm{~nm}$. 


\section{SDS-PAGE and in-gel fluorescence}

SDS-PAGE separation of proteins and in-gel fluorescence were done as previously described (2, 3, 4, 5,). Imaging of SDS-PAGE gels were performed using the LAS4000 imager (GE Healthcare, USA).

\section{Conclusion}

Successful application of biomimetic membrane technology based on the use of nano-scale functional additives in the form of channel proteins or artificially made channel structures depends on the ability to up-scale the processes involved in manufacturing. We have demonstrated how the classical TFC membrane design can be adapted to accommodate the use of aquaporin proteins in a variety of form factors suited for specific applications. In terms of large scale membrane protein production, we have developed the framework for making batch amounts which are compatible with large scale production of biomimetic membranes for water purification. Specifically, we have been able to optimize expression and purification procedures and demonstrate that expression levels around $45 \mathrm{~g}$ per 100 liter fermentation liquid are within reach based on the His ${ }_{8}$ GFP-AqpZ expression in E. coli.

\section{Acknowledgements}

PAP and CHN acknowledge support from the IBISS and MEMENTO projects from Innovation Fund Denmark.

\section{Declaration of financial interests}

PAP and CHN are financially associated with Aquaporin A/S Denmark. SAL is financially associated with Aquaporin Asia Pte, Ltd, Singapore.

\section{References}

1. Nielsen, C.H., Biomimetic membranes for sensor and separation applications. Anal Bioanal Chem, 2009. 395: p. 697-718. 
2. Tang, C., et al., Biomimetic aquaporin membranes coming of age. Desalination, 2015. 368: p. 89-105.

3. Tang, C.Y., et al., Desalination by biomimetic aquaporin membranes: Review of status and prospects. Desalination, 2013. 308: p. 34-40.

4. Baker, R.W., Membrane Technology and Applications 2.ed. 2004, Chichester: John Wiley \& Sons, Ldt. 538.

5. Cath, T.Y., A.E. Childress, and M. Elimelech, Forward osmosis: principles, applications and recent developments. J.Mem.Sci., 2006. 281: p. 70-87.

6. Tang, C.Y., et al., Coupled effects of internal concentration polarization and fouling on flux behaviour of forward osmosis membranes during humic acid filtration. J. Membr. Sci., 2010. 354: p. 123-133.

7. Petersen, R.J., Composite reverse osmosis and nanofiltration membranes. J. Membr. Sci, 1993. 83: $p$. 81-150.

8. Zhao, Y., et al., Synthesis of Robust and High-performance Aquaporin based Biomimetic Membrane by Interfacial Polymerization - Membrane Preparation and RO Performance Characterization J. Membr. Sci., 2012. 423-424: p. 422-428.

9. Chou, S., et al., Characteristics and potential applications of a novel forward osmosis hollow fiber membrane. Desalination, 2010. 261: p. 365-372.

10. Petrotos, K.B., et al., Osmotic concentration of liquid foods. J. Food. Eng., 2001. 49: p. 201-206.

11. Rastogi, N., K., Opportunities and Challenges in Application of Forward Osmosis in Food Processing Critical Reviews in Food Science and Nutrition 2016. 56: p. 266-291.

12. Terefe, N., S., et al., Forward Osmosis: A Novel Membrane Separation Technology of Relevance to Food and Related Industries in Innovative Food Processing Technologies, K. Knoerzer, P. Juliano, and G. Smithers, Editors. 2016, Elsevier. p. 177-205.

13. Pak, T., The coconut Handbook: Technology, Engineering, Agriculture. 2016: Tetra Pak International S.A. 1-183.

14. Henderson, S., Use of medium chain triglycerides for the treatment and prevention of alzheimer's disease and other diseases resulting from reduced neuronal metabolism II. . 2004.

15. Engelhardt, S., A. Sadek, and S. Duirk, Rejection of trace organic water contaminants by an Aquaporinbased biomimetic hollow fiber membrane. Separation and Purification Technology, 2018. 197: p. 170177.

16. Studier, F.W. and B.A. Moffatt, Use of bacteriophage T7 RNA polymerase to direct selective high-level expression of cloned genes. J. Mol. Biol., 1986. 189: p. 113-130.

17. Bomholt, J., et al., Production of human aquaporin-1 in Saccharomyces cerevisiae to a high membrane density. PLoS One, 2013. 8: p. e56431 (9p).

18. Molbaek, K., et al., The first reported high yield purification of full length and functional tetrameric hERG K+ channels Proc. Natl. Acad. Sci., 2014: p. (submitted).

19. P., S.-P. and P. P.A., Saccharomyces cerevisiae-based platform for rapid production and evaluation of eukaryotic nutrient transporters and transceptors for biochemical studies and crystallography. PLoS One 2013. 4: p. e76851.

20. Bjørkskov FB, et al., Purification and functional comparison of nine human Aquaporins produced in Saccharomyces cerevisiae for the purpose of biophysical characterization. Sci Rep., 2017. 7: p.:16899.

21. Kawate T and G. E., Fluorescence-detection size-exclusion chromatography for precrystallization screening of integral membrane proteins. Structure, 2006. 14: p. 673-681. 
Paper prepared for Faraday Discussions

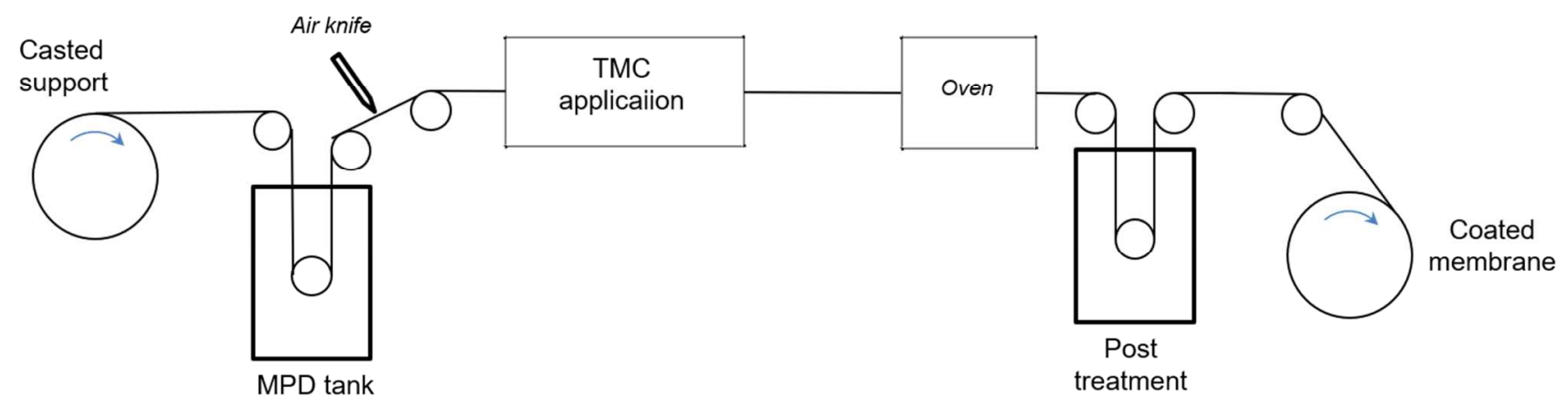


Paper prepared for Faraday Discussions

Figure 1. Outline of the coating process. For explanation see text. 


\section{Paper prepared for Faraday Discussions}

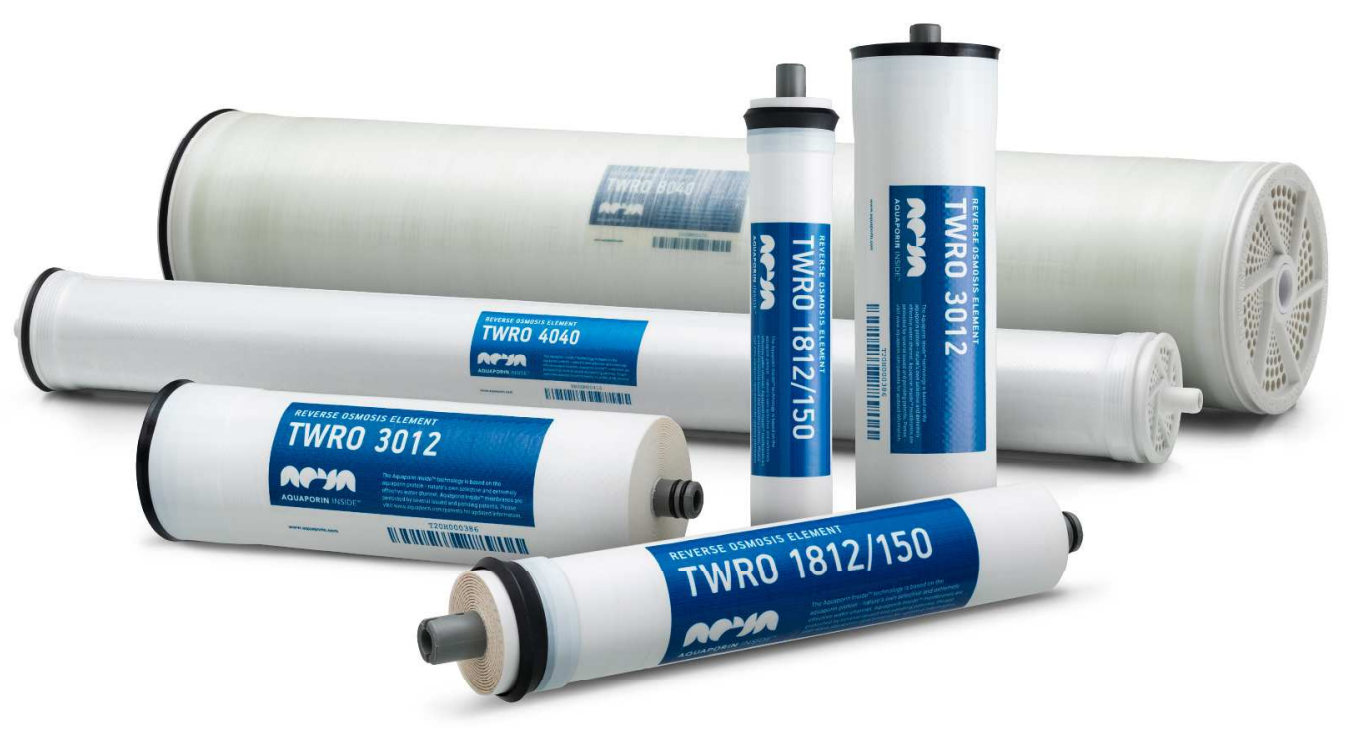

Figure 2: TW RO aquaporin membrane elements in sizes 1812, 3012, 4040 and 8040 form factors. The $1812 / 150$ module shown has a water permeability of 150 Gallons per day equivalent to 24 liter/hour at a pressure of $0.34 \mathrm{MPa}$ and $25^{\circ} \mathrm{C}$ with $15 \%$ recovery. Picture courtesy Aquaporin A/S. 


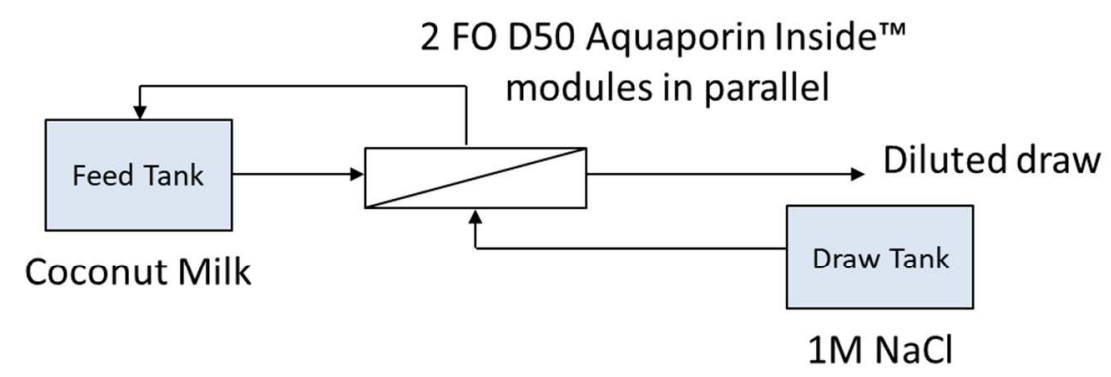

Figure 3. FO up-concentration of coconut milk with batch feed and continuous draw in a co-current flow arrangement. Feed solution: $10 \mathrm{~kg}$ coconut milk (24\% fat content). Draw solution: $1 \mathrm{M} \mathrm{NaCl}$ solution. Membrane: Two Aquaporin Inside ${ }^{\mathrm{TM}}$ D50 Tubular FO modules in parallel $\left(0.7 \mathrm{~m}^{2}\right.$ total membrane area). Feed flow: 0.7 LPM (peristaltic pump) per D50 (lumen flow). Draw flow: 0.5LPM (gearing pump) per D50 (shell flow). Feed and Draw inlet pressures maintained at $<1$ and $<0.1$ bar respectively. Experiments were conducted at an ambient temperature of $17^{\circ} \mathrm{C}$. 


\section{Paper prepared for Faraday Discussions}

a)

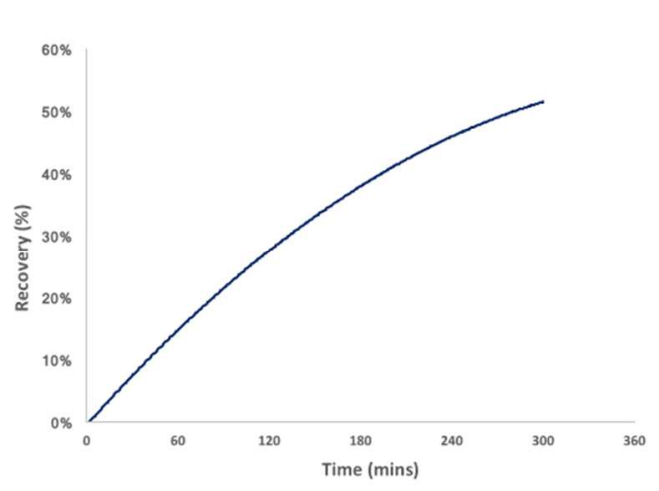

c)

\begin{tabular}{ll}
\hline Step & Duration \\
$10 \%$ citric acid recirculation rinse & 30 mins \\
$10 \%$ ethanol recirculation rinse & 30 mins \\
RO water recirculation rinse & 30 mins \\
25 L RO water flush & As required \\
\hline
\end{tabular}

b)

d)
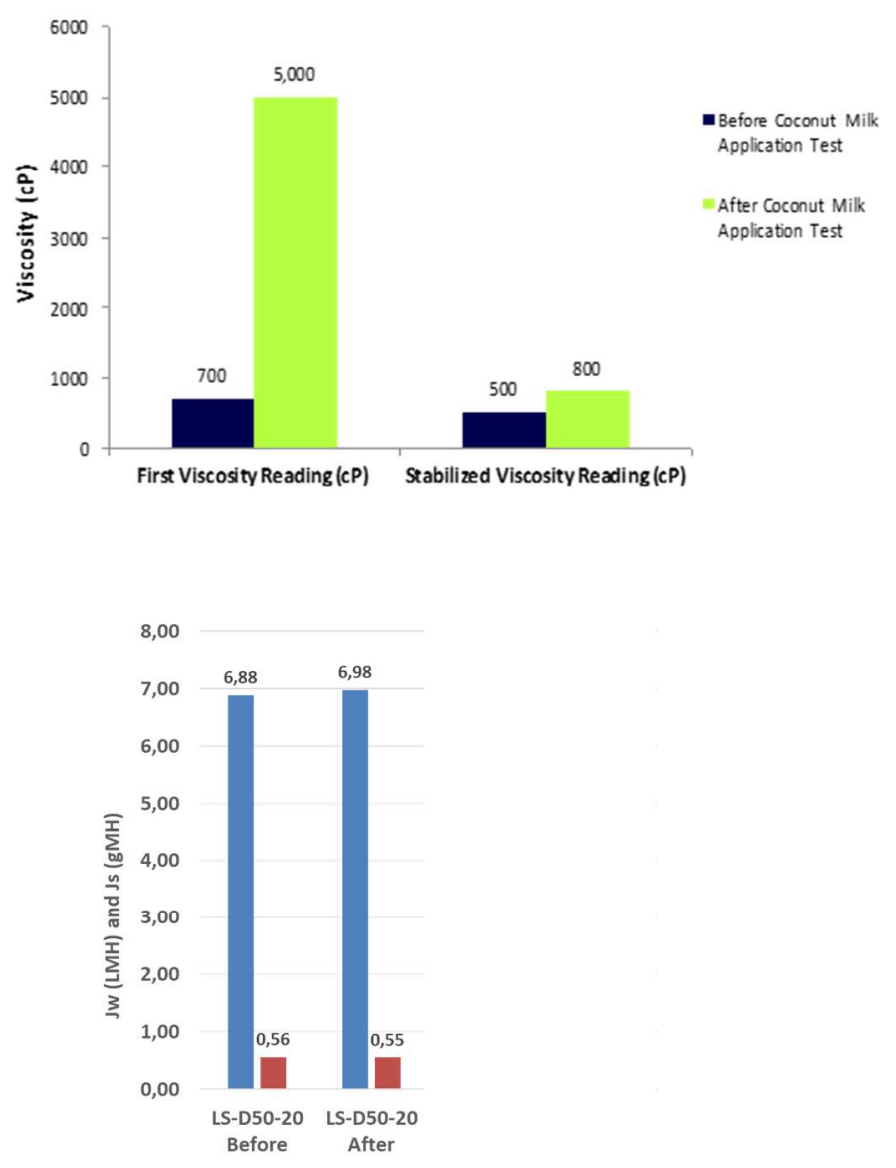

Figure 4. (a): FO up-concentration of coconut milk. Recovery as a function of time. (b): Viscosity measurements before and after FO up-concentration. (c): Cleaning protocol used. (d): Membrane integrity tests performed with DI water as Feed and $1 \mathrm{M} \mathrm{NaCl}$ as Draw. 


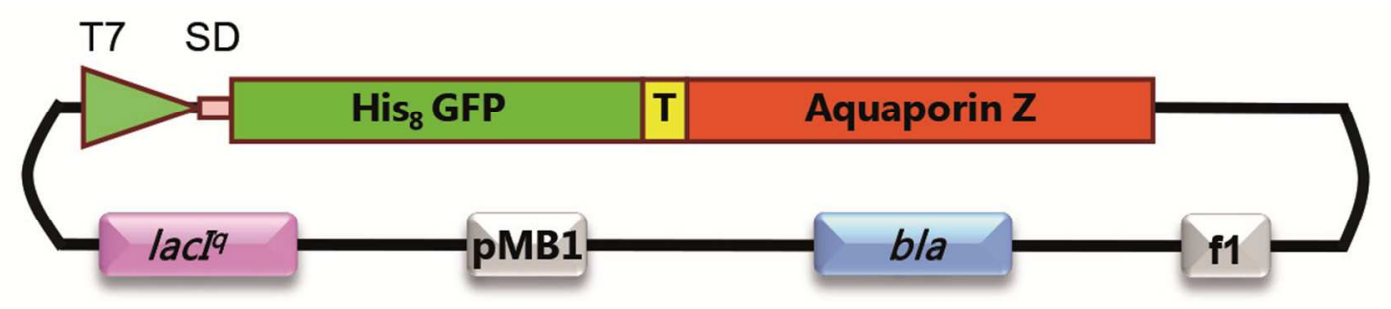

Figure 5: Structural map of the plasmid used for production of AqpZ N-terminally fused to a His ${ }_{8}$-GFP tag. T7, the T7 promoter; SD, an optimal E.coli Shine-Dalgarno sequence; His 8 -GFP, an E.coli optimized GFP carrying eight histines at the N-terminal; T, a cleavage site for the Tobacco Etch Virus Protease; Aquaporin Z, the native AqpZ from E. coli; lacI ${ }^{\mathrm{q}}$, an allele overexpressing the lac repressor from E. coli; pMB1, the pMB1 origin of replication; bla, a $\beta$-lactamase gene encoding ampicillin resistance; $\mathrm{fl}$, the $\mathrm{fl}$ origin of replication. 


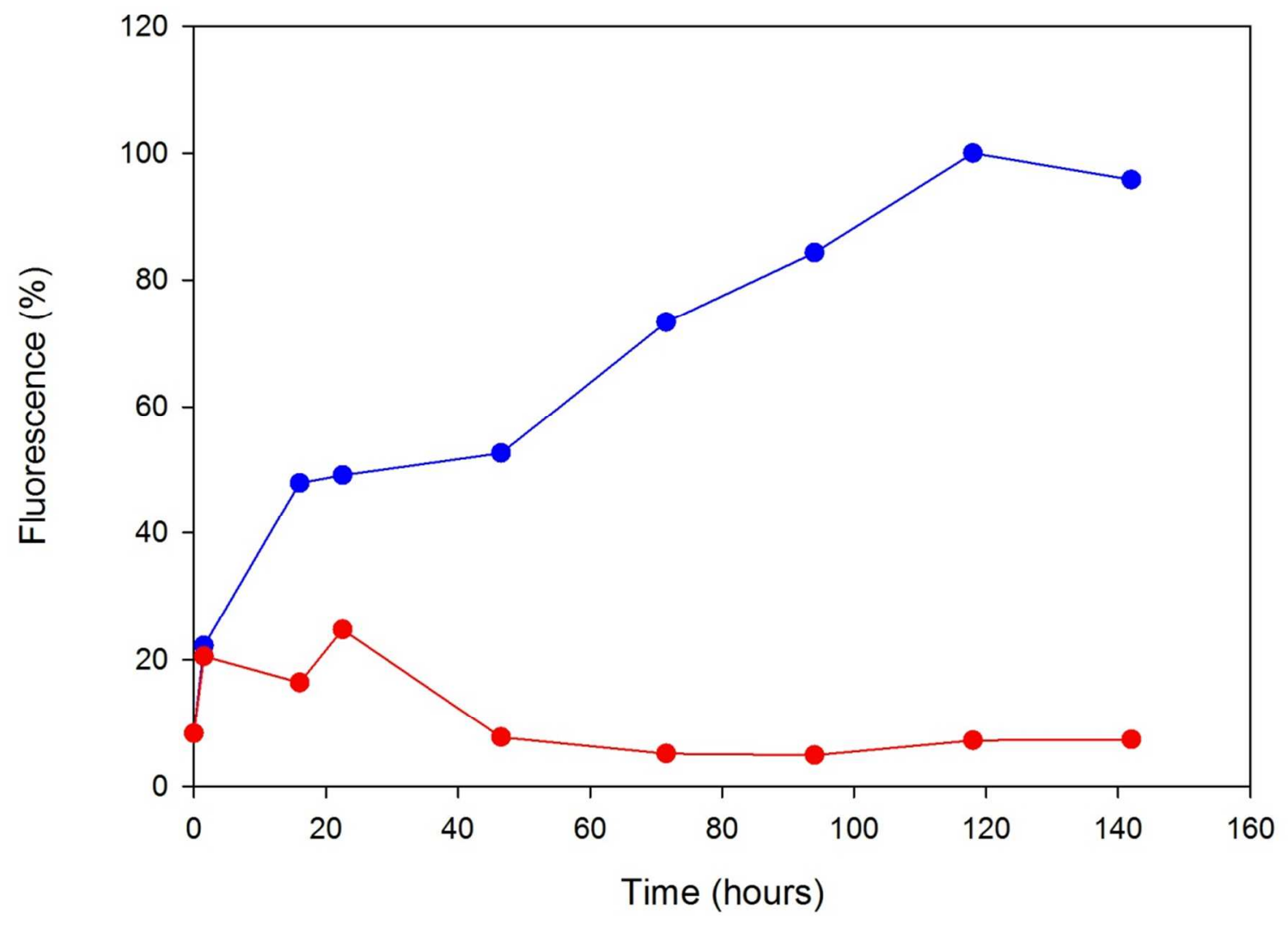

Figure 6: Temperature dependent accumulation of His 8 -GFP-AqpZ in the BL21(DE3) host strain. Cells were grown as described in Materials and Methods at room temperature until an optical density $\left(\mathrm{OD}_{450}=0.6\right)$. The culture was subsequently divided in two and induced with $1 \mathrm{mM}$ IPTG after thermo equilibration at $15^{\circ} \mathrm{C}$ and $37^{\circ} \mathrm{C}$, respectively. GFP fluorescence was measured in one $\mathrm{OD}_{450}$ unit at the indicated times before and after induction with IPTG. 


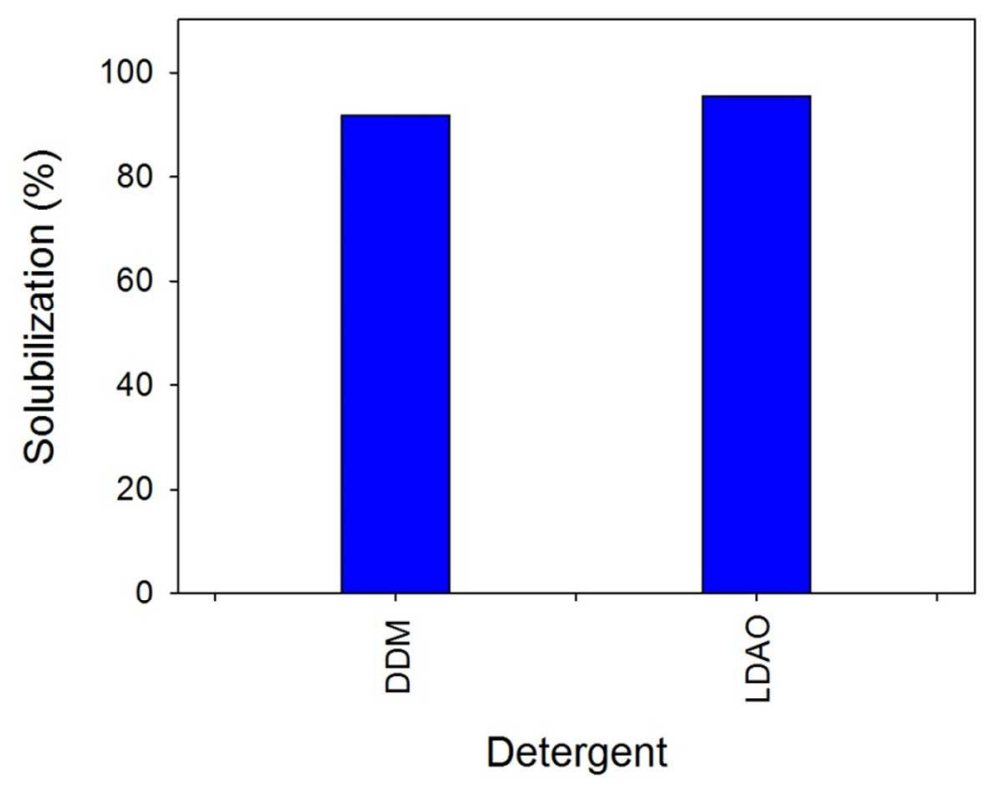

Figure 7: Solubilization of His 8 -GFP-AqpZ from purified E. coli membranes. Crude E. coli membranes were incubated for one hour at $4^{\circ} \mathrm{C}$ with the indicated detergents at a protein to detergent ratio of one to three. The solubilized His 8 -GFP-AqpZ protein was quantified by measuring the GFP fluorescence of the supernatant after ultracentrifugation at $160.000 \mathrm{~g}$ and normalizing to the entire fluorescence of the sample used for solubilization. 

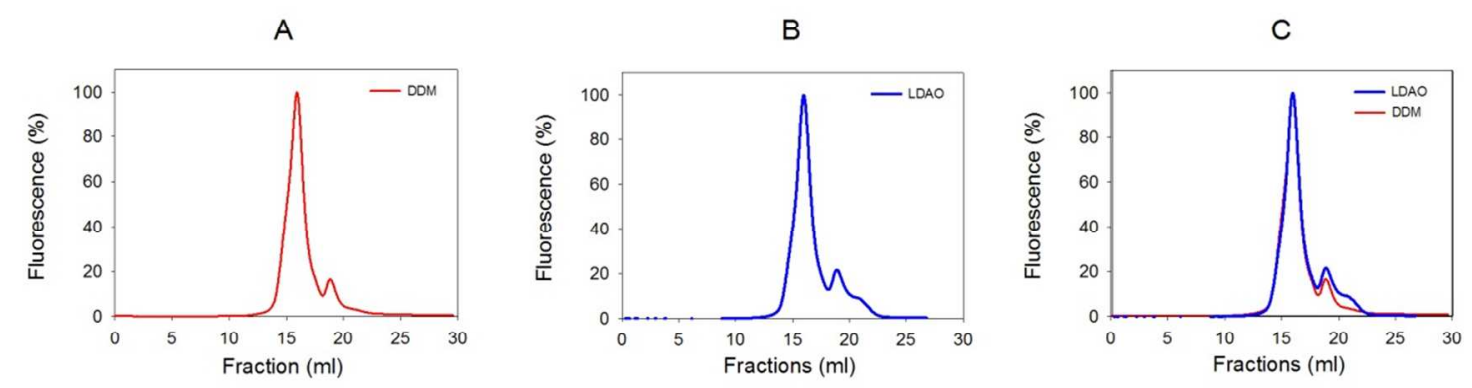

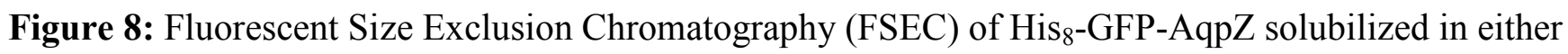
DDM or LDAO at a protein to detergent ratio of one to three. The solubilized proteins were separated in a Superose 6 increase 10/300 column as described in Materials and Methods. Fluorescence is presented as percentage of the fluorescence units measured in the peak. A, FSEC profile of His -GFP- $_{8}$ AqpZ solubilized in DDM; B, FSEC profile of His 8 -GFP-AqpZ solubilized in LDAO; $\mathbf{C}$, overlay of the FSEC profiles obtained in A and B. The major peak corresponds to a globular protein with a molecular mass around 200.000 corresponding to the expected molecular weight of a His8-GFP-AqpZ tetramer. The minor peak observed in each FSEC profile originates from GFP liberated from the fusion protein by proteolysis during solubilization. 

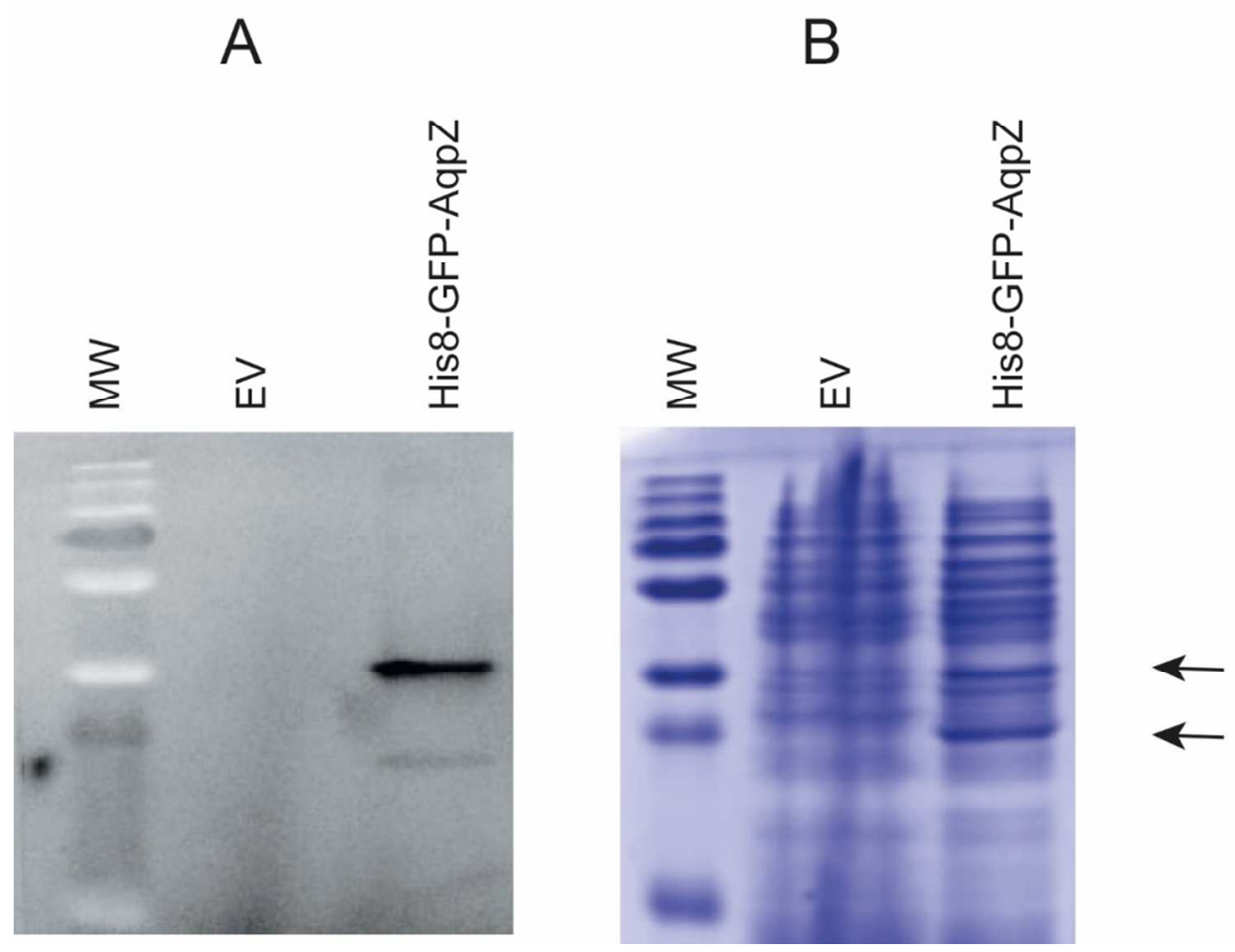

Figure 9: In-gel fluorescence (A) and Coomassie staining (B) of E.coli cells expressing $\mathrm{His}_{8}$-GFPAqpZ for 48 hours at $15^{\circ} \mathrm{C}$ or cells carrying only the empty expression vector (EV) and consequently not expressing any GFP-tagged AqpZ. The protein content of intact cells treated as described in Materials and Methods were separated directly by SDS-PAGE. Arrows indicate the position of the two bands in the Coomassie gel that emit fluorescence. The PageRuler marker (MW) represents from the top of the gel molecular weights of $250 \mathrm{kDa}, 130 \mathrm{kDa}, 100 \mathrm{kDa}, 70 \mathrm{kDa}, 55 \mathrm{kDa}, 35 \mathrm{kDa}, 25 \mathrm{kDa}$ and $15 \mathrm{kDa}$, respectively. 


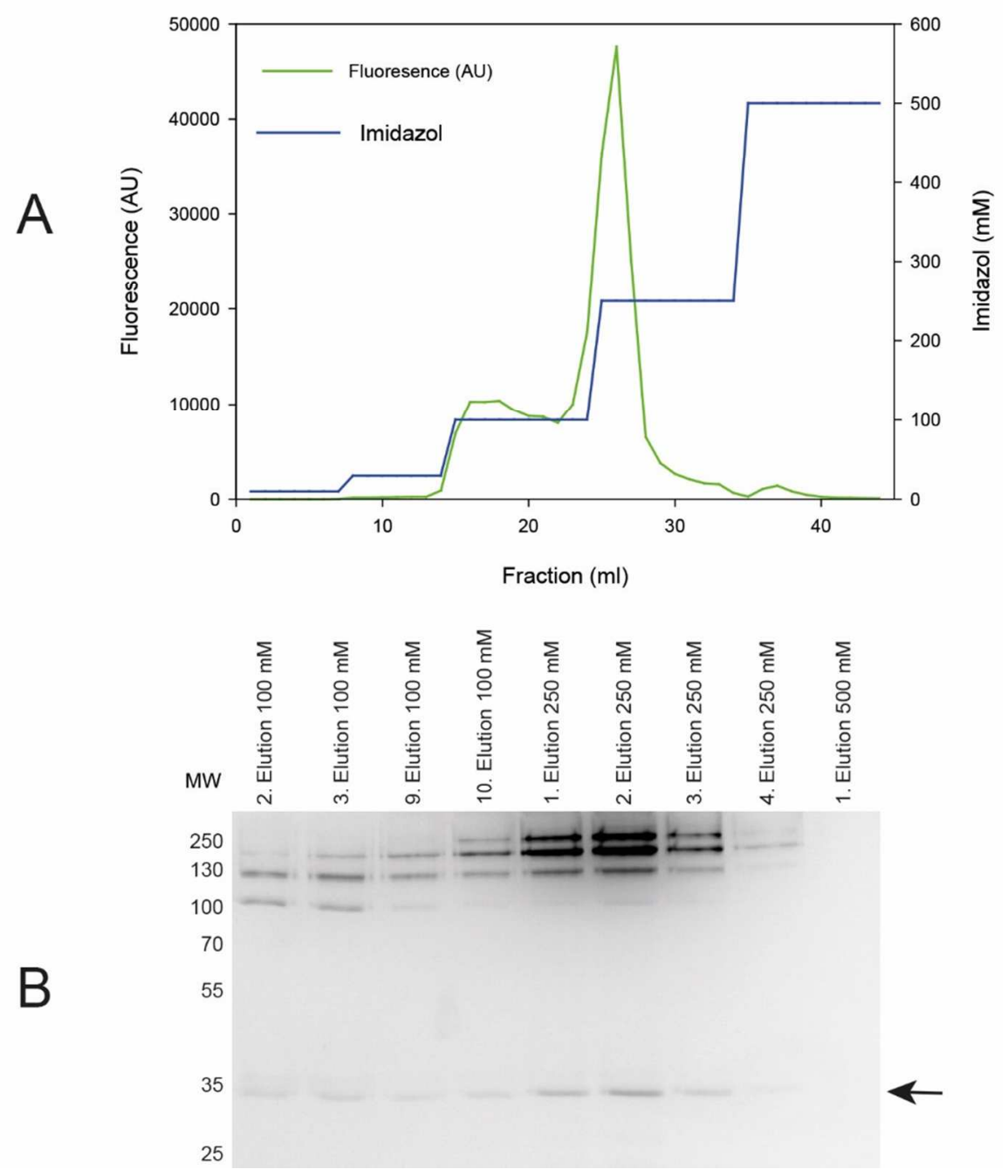

Figure 10: A, elution profile of $\mathrm{His}_{8}$-GFP-AqpZ during purification by Ni-affinity chromatography. B, in-gel fluorescence of some of the fractions from "A". An arrow indicates the position of the $\mathrm{His}_{8}$ GFP-AqpZ fusion protein migrating at the expected $33 \mathrm{kDa}$. 